\title{
Power and Politics in the Global Health Landscape: Beliefs, Competition and Negotiation Among Global Advocacy Coalitions in the Policy-Making Process
}

\section{Lori McDougall ${ }^{*}$}

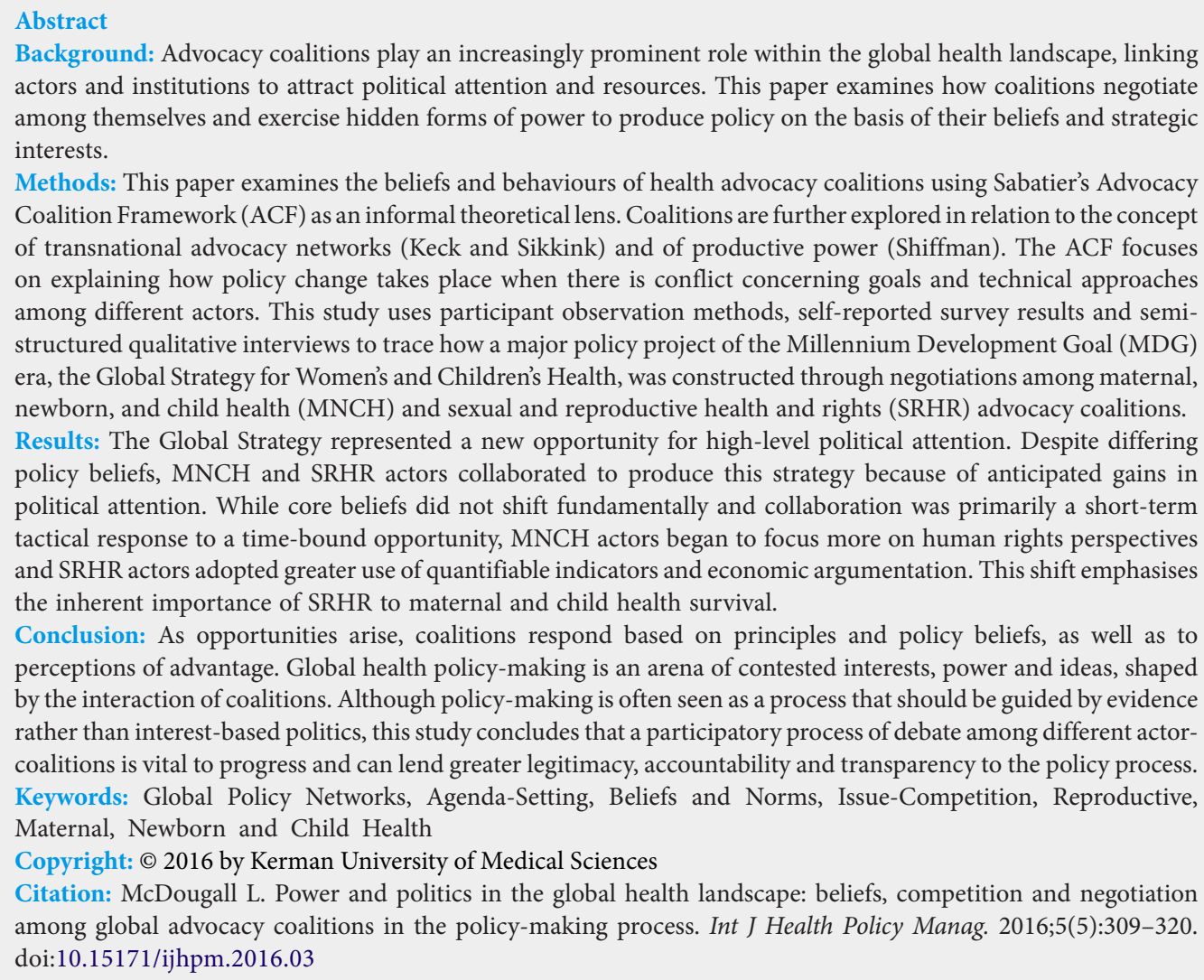
actors and institutions to attract political attention and resources. This paper examines how coalitions negotiate among themselves and exercise hidden forms of power to produce policy on the basis of their beliefs and strategic interests.

Methods: This paper examines the beliefs and behaviours of health advocacy coalitions using Sabatier's Advocacy Coalition Framework (ACF) as an informal theoretical lens. Coalitions are further explored in relation to the concept of transnational advocacy networks (Keck and Sikkink) and of productive power (Shiffman). The ACF focuses on explaining how policy change takes place when there is conflict concerning goals and technical approaches among different actors. This study uses participant observation methods, self-reported survey results and semistructured qualitative interviews to trace how a major policy project of the Millennium Development Goal (MDG) era, the Global Strategy for Women's and Children's Health, was constructed through negotiations among maternal, newborn, and child health (MNCH) and sexual and reproductive health and rights (SRHR) advocacy coalitions. Results: The Global Strategy represented a new opportunity for high-level political attention. Despite differing policy beliefs, MNCH and SRHR actors collaborated to produce this strategy because of anticipated gains in political attention. While core beliefs did not shift fundamentally and collaboration was primarily a short-term tactical response to a time-bound opportunity, $\mathrm{MNCH}$ actors began to focus more on human rights perspectives and SRHR actors adopted greater use of quantifiable indicators and economic argumentation. This shift emphasises the inherent importance of SRHR to maternal and child health survival.

Conclusion: As opportunities arise, coalitions respond based on principles and policy beliefs, as well as to perceptions of advantage. Global health policy-making is an arena of contested interests, power and ideas, shaped by the interaction of coalitions. Although policy-making is often seen as a process that should be guided by evidence rather than interest-based politics, this study concludes that a participatory process of debate among different actorcoalitions is vital to progress and can lend greater legitimacy, accountability and transparency to the policy process. Keywords: Global Policy Networks, Agenda-Setting, Beliefs and Norms, Issue-Competition, Reproductive, Maternal, Newborn and Child Health

Copyright: (c) 2016 by Kerman University of Medical Sciences

Citation: McDougall L. Power and politics in the global health landscape: beliefs, competition and negotiation among global advocacy coalitions in the policy-making process. Int J Health Policy Manag. 2016;5(5):309-320. doi:10.15171/ijhpm.2016.03

\section{Article History:}

Received: 9 July 2015

Accepted: 6 January 2016

ePublished: 30 January 2016

\section{Key Messages}

Implications for policy makers

- The increase of global resources for reproductive, maternal, newborn, and child health (RMNCH) is a result of intensified coordination of actors in the effort to achieve the Millennium Development Goals (MDGs).

- Understanding how transnational policy coalitions think, compete and negotiate with each other is vital to understanding how they have come to wield increasing influence in global health at a time of declining state dominance.

- Global-level policy-making is legitimated and made more accountable by the participation of multi-constituency actor coalitions, including coalitions in which government representatives participate.

- In global public health, scientific, evidence-based policy-making is frequently presented as an ideal, asserting principles over politics; this approach discourages recognition and assessment of the productive role of power and politics in policy-making, particularly important to debates about equity and human rights.

- Supporting and enabling platforms for public debate at the global level, including through policy advocacy coalitions, is essential to improvements in public health and lends greater transparency to global policy-making.

Implications for public

New opportunities have arisen for public participation and debate in global health through the growing scale and reach of cross-border advocacy coalitions. In the domain of women's and children's health, the implementation of the Global Strategy promoted the allocation of new resources and greater accountability. At the same time, competition among coalitions within this community continues to shape how resources for women's and children's health are raised and used. This has created tension that exposes the global health policy-making process as a fundamentally political process that cannot be understood purely in terms of science and evidence. Competition and debate enables a wider democratic process to prevail and creates opportunities for participation and greater accountability, including those most affected by health policy decisions. 


\section{Background}

The rising number and power of transnational partnerships in the global health arena have prompted greater attention to who makes global health policy, how this happens, and with what effects. ${ }^{1,2}$ Actor-groups within these partnerships prioritise differing forms of knowledge, hold differing values, and assert differing behaviours. Advocacy coalitions compete against each other for political attention by constructing persuasive narratives of problems and solutions. In the midst of this, policy-makers are faced with a widening array of competing issues and claims, yet have a finite set of resources to select, prioritise and act upon these. Therefore, policymaking is a fundamentally political and social process in the field of global health, despite the frequent assertion that global health policy should rest on a scientifically neutral, evidence-based foundation, marked by principled decisionmaking, rather than interest-based politics. ${ }^{3}$

Indeed for some, evidence-based advocacy is seen as deliberately political in nature, projecting public health as an outcome of correctly applied technical and operational solutions, and downplaying the complexities of social and political change. ${ }^{4}$ What is accepted as evidence-based in global public health areas often rests on the power of scientific and technical elites to determine the themes and terms of debate, which can exclude non-technical actors or non-elites from that process, creating a "de-democratising" effect in the policy-making process. $^{5}$

Central to understanding how agenda-setting takes place and shapes our capacity to assess the legitimacy of health agendas is understanding how power is constructed and claimed by global health actors, including the advocacy coalitions through which they operate. Shiffman, for instance, draws our attention to three types of "power" in global health. ${ }^{6}$ 'Compulsive' power is easily seen, such as bilateral donors tying health aid to trade. Less visible are other types of power, including those based on epistemic or normative concerns rather than material interests. An example of this type of power is 'structural': in the context of a relationship between actors structural power enlarges the capacities of some while reducing those of others. Another is 'productive' power, such as how issues are deliberately framed and presented to shape the thinking and behaviours of others. ${ }^{6}$

Understanding how participants in the field of global health - and in particular, the area of sexual, reproductive, maternal, newborn, child and adolescent health - express their power to influence political attention is the subject of this paper. Nearly 100 new private-public 'global health initiatives' have been created over the past 15 years, bringing new financing, technical support, innovation, and advocacy capacity to global health. ${ }^{7}$ These private-public initiatives have also brought new challenges to health governance, as a wide range of non-state actors assumed key positions of influence over a growing set of resources. ${ }^{8,9}$ In response to this changing landscape of actors, there have been calls for stronger global health governance, especially in light of the cross-border nature of the issues and the need for greater solidarity and accountability among actors to address health problems and their social and economic determinants. ${ }^{10-12}$

While examples of compulsory and structural power are reasonably apparent in global health, ${ }^{6}$ productive power may be less visible, and therefore of particular interest in understanding the norms and behaviours of global networks. This paper focuses on the case of the Global Strategy for Women's and Children's Health (2010-2015) document, developed by policy actors from across a broad range of sexual, reproductive, maternal, newborn, and child health alliances. Launched in 2010 as a five-year plan by United Nations (UN) Secretary-General Ban Ki-moon, the Global Strategy catalysed unprecedented political support in meeting the challenge of meeting the health Millennium Development Goals (MDGs), especially MDG 4 and MDG $5^{[1]} .{ }^{13}$

The Global Strategy is presented here as the outcome of negotiations among competing advocacy coalitions, each motivated by a set of core policy beliefs. To assess the Global Strategy, this paper adopts key concepts from Sabatier and Jenkins-Smith's Advocacy Coalition Framework (ACF), ${ }^{14,15}$ which focuses on explaining how policy change takes place when there is conflict concerning goals and technical approaches among different actor-groups. Coalition behaviours based on core beliefs is a key concept of this approach, including how such beliefs shift over time through policy learnings.

However, since the main objective of this paper is examining how productive power is used by global health networks in influencing policy, the ACF is treated only as a lens through which competitive coalition behaviours are viewed and interpreted rather than as an explanatory theory. The reason for this alternative interpretation is that the ACF is customarily applied to pluralistic political systems within nation-states rather than complex transnational governance landscapes.

Sabatier and Jenkins-Smith define an advocacy coalition as a set of "actors from a variety of public and private institutions at all levels of government who share a set of basic beliefs (policy goals plus causal and other perceptions) and who seek to manipulate the rules, budgets and personnel of governmental institutions in order to achieve these goals over time."14 In the global case examined by this paper, coalitions are understood less as geographically bounded and operating with formal political systems, but rather as loose collections of alliances made up of committed individual and institutional policy actors with dense inter-organisational and interpersonal ties working across borders to influence policy. This more informal concept of advocacy coalitions aligns with Della Porta and Diani, who identify these as informal networks of collective action with clear common goals, but not necessarily backed by formal identity links. ${ }^{16}$ Therefore, the 'maternal, newborn, and child health $(\mathrm{MNCH})$ coalition' is understood to be made up of a large number of alliances operating at different scales (from sub-national to global), united by a primary concern to reduce maternal and/or child mortality in line with the focus of the MDG on health as a means of poverty reduction. ${ }^{17}$ Alliance members include nongovernmental organizations (NGOs), health professional associations, academic institutions, private and public donors and government institutions. Similarly, the 'sexual and reproductive health and rights (SRHR) coalition' unites a vast number of such private-public alliances concerned primarily with advancing the health and rights of women, including by securing such entitlements as contraception and safe abortion 
services. This rights-based focus is expressed through shared goals emerging from the International Conference on Population and Development (ICPD) in Cairo in 1994 and the Fourth World Conference on Women in Beijing in 1995. It is important to be clear that neither coalition exists as a formally constituted and governed entity; each is a composite of a large number of different alliances and partners operating at different scale, sharing similar beliefs and advocacy approaches. Further, in practice, there is substantial overlap in policy beliefs between coalitions - many $\mathrm{MNCH}$ coalition members would not define themselves in opposition to the SHRH coalition, and vice versa, given the naturally codependent relationship between women's and children's health. As described by some ACF scholars and apt in this case is the concept of coalitions consisting of solid core beliefs "with fuzzy edges." ${ }^{18}$ Further, within coalitions, there is substantial disparity of beliefs on secondary aspects, notably within the MNCH coalition, with longstanding tensions between those primarily concerned with maternal health rather than newborn health or child health, or vice versa; despite overarching core beliefs about the importance of reducing preventable mortality and the value of taking an integrated approach to maternal and child health.

The Advocacy Coalition Framework and Global Health Networks

In developing the ACF, Sabatier and Jenkins-Smith questioned the depiction of policy-making as a sequence of seamless top-down sub-processes or stages, flowing forward from agenda setting to policy formulation, policy implementation, and policy evaluation and reformulation, and dominated largely by the actions of government leaders. ${ }^{15}$ In response, they developed a hypothetical framework that sought to reconcile top-down and bottom-up views, explaining how the interaction of different actor-groups at different levels (eg, scientists and technical experts, media, civil society, etc, together with government) could move the policy process through the competitive behaviours of coordinated action groups, or coalitions, formed through shared beliefs and values. Such behaviours include the deliberate "framing" of ideas and beliefs shared within the coalition to portray issues in persuasive way, ${ }^{19}$ as well as the opportunistic use of 'policy windows' as they open up in order to secure coalition dominance. $^{20}$

Belief systems are defined by Jenkins-Smith and Sabatier as sets of value priorities and causal assumptions about how to realise them. ${ }^{21}$ While actors are assumed to be instrumentally rational - ie, using all possible resources to pursue their goals - the framework draws more on cognitive and social psychology than economics in highlighting the biases and constraints of individuals in perceiving the world and processing that information. ${ }^{15}$

Sabatier and Jenkins-Smith propose a set of nine linked hypotheses addressing three main themes. ${ }^{15}$ The first theme concerns the nature of advocacy coalitions: that there are shared normative and causal beliefs that act as the 'glue' holding together members of advocacy coalitions, ie, formal or informal networks through which actors build resources and strategies to influence policy, competing with other such coalitions for dominance. The second theme addresses how policy change occurs, including the notion of external events (shocks) as necessary but insufficient triggers for policy change. The third theme relates to the contribution of policyoriented learning across coalitions, including conditions under which change occurs and the contribution of quantitative evidence in relation to quantifiable problems, and especially when professional forums exist for technical consensusbuilding across different coalitions. ${ }^{15,21}$ Both the ACF and Shiffman's concept of hidden 'productive power' revolve around the concept of the deliberate use of ideas and beliefs as structuring forces for political gain, and so are treated in a complementary fashion in this paper.

In Sabatier and Jenkins-Smith's view, belief systems operate on three levels: deep core beliefs (normative beliefs widely shared in the world and not specific to individual policy subsystems, such as the nature of good versus evil); policy core beliefs (normative beliefs and causal perceptions specific to particular coalitions, such as shared ideas about of the severity and causes of a particular problem); and secondary beliefs (a large set of narrower beliefs about the seriousness of the problem or the relative importance of various causal factors) ${ }^{21}$ Although deep core beliefs are nearly impossible to change since they are rooted in one's fundamental perceptions about the nature of the world, Sabatier and Jenkins-Smith believe that policy core beliefs can shift gradually over longer periods of time (a decade or more) provoking major policy change, while secondary beliefs can shift more quickly, creating minor policy shifts in response to certain events or shocks (Figure). ${ }^{15}$

Context matters, therefore, in Sabatier and Jenkins-Smith's view of policy-making. ${ }^{15}$ Context provides relatively stable parameters that shape the resources and constraints of the policy sub-system ${ }^{[2]}$, as well as more dynamic event-based variables, such as changes in government, economic outlook, public opinion, or policy decisions of other policy subsystems, that directly shape secondary beliefs and minor policy changes.

\section{How Do Global Networks Interact?}

While Sabatier and Jenkins-Smith understand the term "sub-system" to refer to the substantive and geographic scope of institutions that structure interaction, 22 this paper applies a global lens to the concept, moving beyond the restriction of physical 'territories' to focus on global health policy subsystems and their political behaviours. While the ACF has been most often applied to domestic political systems, the global setting of this case, with multiple 'fuzzy-edged' coalitions and multiple geographic scales, demands a more flexible use of the framework.

To begin, we borrow from Keck and Sikkink's concept of transnational advocacy networks to depict the global reproductive, maternal, newborn, child and adolescent health policy sub-system as one characterised by voluntary, reciprocal and horizontal patterns of communication and exchange. ${ }^{1}$ In using the term "transnational advocacy networks," Keck and Sikkink focus rather restrictively ${ }^{23}$ on networks of non-state actors seeking to influence the agendas of states, multilateral agencies and corporations through the use of collective information, ideas and strategies. ${ }^{1}$ However, traditional ideas of dominance, embedded in "international health" 


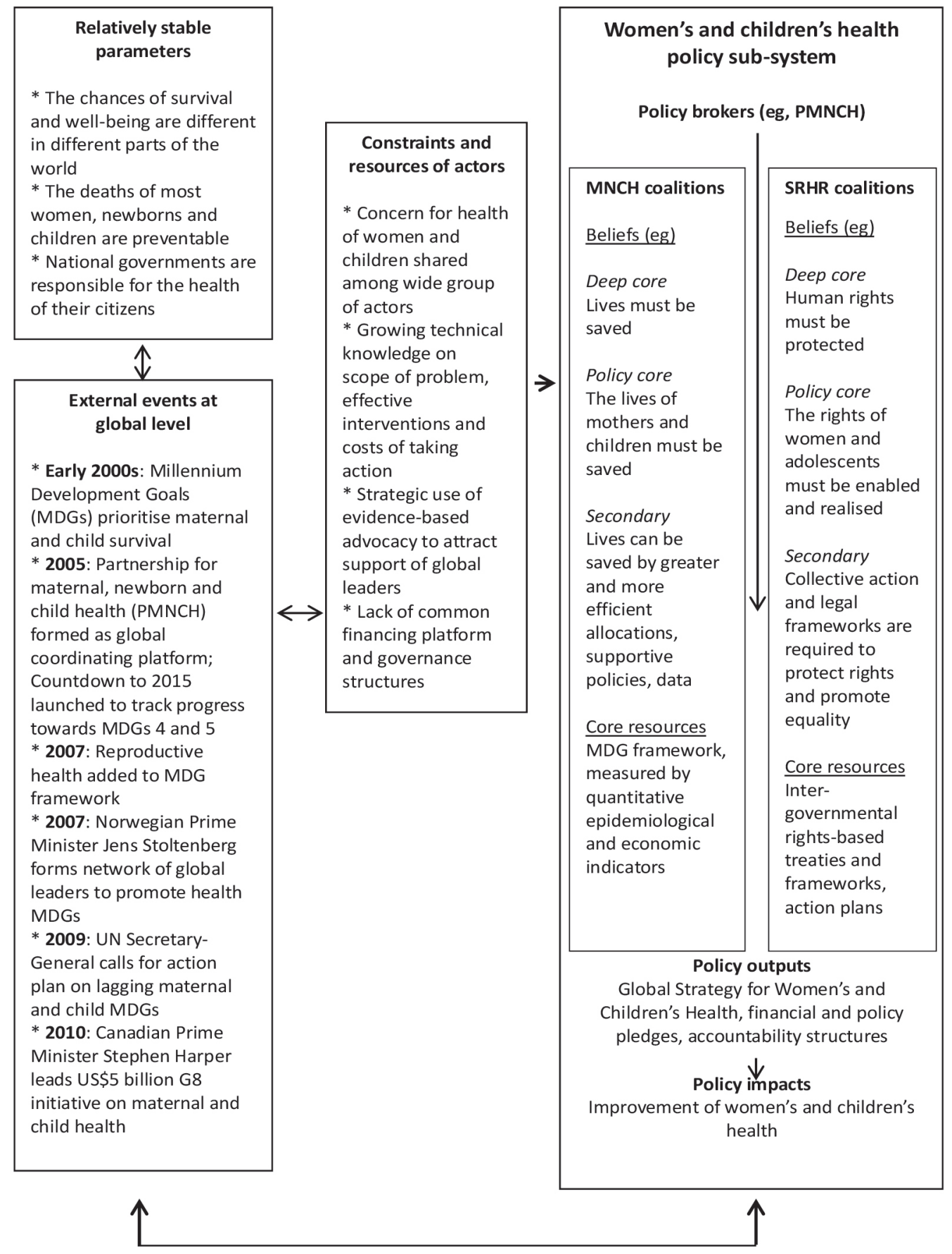

Figure. The Global Strategy for Women's and Children's Health Analysed Through Sabatier's Advocacy Coalition Framework.

and bilateral development aid to low-income countries, are challenged by the rise of "global health" in the past 15 years, with its constituency-based partnerships and networks of public and private actors, including low-income countries themselves. ${ }^{24}$ This more participatory if complex concept of health, in which many actor-networks assert differing forms of influence at different levels, challenges traditional ideas of who holds power over whom and how, raising questions of governance and accountability. ${ }^{2,11}$

Accordingly, this paper describes a scenario in which a global health policy sub-system, composed of thousands of both state and non-state actors, governments, NGOs, UN agencies, private businesses, health professionals, academics, the media, etc - divide into disparate coalitions that cohere on the basis of what Keck and Sikkink call "shared ideas and values" within "transnational advocacy networks." These informal "networks of collective action," combined with Della Porta and Diani's interpretation of the term 'coalition' - are based on relations of voluntary exchange and dense personal ties. ${ }^{16}$ For the MNCH coalition, a deep core belief is that the lives of mothers and children must be saved, and preventable mortality, therefore, reduced. This belief is often framed by the coalition as part of the effort to reach the 2015 poverty reduction targets specified by the MDGs in relation to maternal and child health. On the contrary, the SRHR coalition is primarily concerned with the realisation of human rights. The SRHR coalition believes this cannot happen legitimately through a quantitative target-based framework like the 
MDGs, but by inter-governmental agreements and legislative instruments. Quantitative and "scientific" arguments based on economics and epidemiology, used effectively by the $\mathrm{MNCH}$ coalition to attract political attention, have been less frequently used by the SRHR coalition, whose argumentation revolves often around rights and entitlements.

All actors in this global community operate within an arena determined by relatively stable parameters (Figure). ${ }^{15}$ Sudden events or shifts in external conditions (eg, changes in socioeconomic conditions, governance arrangements, or public opinion) can facilitate policy change, largely in relation to minor or secondary beliefs, rather than core beliefs. However, events themselves are seen by Sabatier and Jenkins-Smith as necessary but insufficient factors to explain policy change produced by such advocacy coalitions or sub-communities. What must also be taken into account is the effect of policy learnings by advocacy coalitions over time as they learn and grow, including shifts in scientific or technical knowledge. ${ }^{22,25}$ Competition and negotiation among coalitions, therefore, is an enduring part of the process of establishing dominance in the policy-making process, with each coalition seeking to translate its own beliefs into policy. Competition takes place on the grounds of the strategic framing of their beliefs (the "productive power" discussed by Shiffman), ${ }^{6}$ as well as the wider set of resources (material, legal, and epistemic) held by each coalition. Often, this competition requires the intervention of policy brokers to mediate conflicts and move the policy process forward..$^{25}$ Policy, therefore, is the outcome of a highly politicised process of ideological competition between multiple policy participants at different scales, influenced by events, scientific evidence and beliefs.

In examining the central questions posed by this paper - eg, how do global coalitions interact to produce policy, and how is productive power used in this process? - the ACF provides a useful lens through which the Global Strategy may be viewed. There are two main reasons why this is so. First, this case examines the causal links between beliefs, values, and behaviours; second, this case focuses on how scientific and technical evidence is used as bargaining power in this process and the role of policy brokers in negotiating consensus between coalitions.

With transnational advocacy networks creating greater links between global, regional, national and sub-national policy processes, ${ }^{1}$ this study follows a small number of other studies ${ }^{23,26}$ in using key concepts of the ACF to examine global political dynamics, including those influenced by the agendasetting power of the MDGs. ${ }^{27,28}$ As such, this study seeks to fill a gap in global health governance literature on the agendasetting power of advocacy coalitions, particularly in relation to women's, children's and adolescents' health, which has attracted substantial attention and resources during the MDG era $(2000-2015){ }^{27,28}$

\section{Methods}

This paper relies on surveys, interviews, document analysis, and participant-observation methods to analyse how policy is produced through coalition behaviours. A case study approach with qualitative methods such as indepth interviews and participant-observation can yield important results when seeking to explain "how" and "why" contemporary phenomena occur, such as the influence of advocacy coalitions in the global policy production process. ${ }^{29}$ Descriptive statistics from survey data are added to this case to triangulate the observations and increase validity.

A primary data source for this paper is the transcripts of 24 semi-structured key-informant interviews conducted by the partnership for maternal, newborn, and child health (PMNCH) with commitment-makers (approximately one hour in length per interview) during April-June 2013. These interviews were designed to follow-up on written responses to a larger survey, described below, and respondents were chosen randomly within seven different constituency groups that had made commitments (ie, governments, donors/foundations, $\mathrm{UN} /$ multilateral, NGOs, health professional associations, private sector, and academic and training institutions). The author was permitted by the Partnership to insert specific questions of relevance ${ }^{[3]}$ for this research paper into the interview guide in order to probe perceptions and beliefs of the respondents about the construction of the Global Strategy and related commitments. The questions were meant to be the same for all key informants (40 in total, representing a third of the respondents who had submitted responses to the written survey); however, in practice, the questions on advocacy were listed at the end of the interview, and time did not always permit full and complete answers. Therefore, 24 transcripts were deemed useable for the purpose of this study, spread across constituency groups as follows: senior representatives of low- and middle-income governments (3 interviews); donor governments (7 interviews); foundations (3 interviews); global health partnerships (3 interviews); private business ( 5 interviews); and NGOs ( 3 interviews). The author was permitted to observe six of these 24 telephone interviews to understand if the questions generated any observable responses of interest for this research, eg, particular emphasis, inflections, hesitations, etc.

Sabatier and Jenkins-Smith's ACF suggests that understanding the process of policy change requires a time perspective of a decade or more in order to see how actors respond to emerging knowledge and alter their strategies accordingly. ${ }^{15}$ To this end, this study draws on a decade of participant-observation of the global health community and the major advocacy coalitions related to women's, children's and adolescents' health within it (2005 to present, during the author's employment with $\mathrm{PMNCH})$. This longitudinal perspective has enabled a detailed understanding of the external context in which the Global Strategy emerged (2005-2009), the interactions between actors and coalitions that led to the creation of this policy project (2009-2010), and the effects created by the Global Strategy since its 2010 launch. It has also enabled the qualitative identification of the disparate coalitions and their observed 'fuzziness.'

These observations were triangulated with the results of two rounds of written survey responses by organisations that had made written commitments to support the implementation of the Global Strategy over the September 2010 to June 2013 period. This data set includes 168 responses in the first round (2012) from 220 possible "commitment-makers", and 120 from a possible 268 in the second round (2013). These responses were solicited by $\mathrm{PMNCH}^{[4]}{ }^{30,31}$; secondary analysis was performed for the purposes of this paper. 
Overall, this study prioritises qualitative methodologies of data analysis, including the selection of codes (key actors, issues, events, global frameworks, behaviours), which were refined in an iterative fashion as the data interpretation process developed in the course of the research. Content analysis of the various data sets was used to examine and triangulate the three data sets. ${ }^{32}$

Given this 'insider' association with the Global Strategy project, bias is assumed in the observation, which this analysis of survey data and key informant interviews attempt to mitigate. As Walt et al suggest, "position can influence the issues that researchers focus on, and, therefore, the research agendas created and the research questions asked." ${ }^{33}$ While 'insider' status may facilitate access to data and the ability to ask more meaningful questions, it disallows the ability to approach research topics from a fresh perspective that can allow new insights.

An additional limitation of this study design is that written and oral data were collected only from those who have made a commitment to the Global Strategy, and, therefore, little is known about the reasons why some institutions do not collaborate in this policy project, and what they perceive as the benefits or limitations of that decision.

\section{Case Study: The Global Strategy for Women's and Children's} Health

The creation of the Global Strategy for Women's and Children's Health is considered to be a successful effort in influencing political priority for women's and children's health. This claim is based on the mobilisation of US\$60 million in financing from a broad range of donors; the creation of new national and global initiatives for lagging issues such as newborn health and family planning; and the creation of a shared accountability framework to monitor resources and results for women's and children's health. ${ }^{34}$

The Global Strategy, developed in 2010, proceeded, in part, from evidence previously agreed by stakeholders through such processes as the High-Level Task Force for Innovative International Financing for Health Systems in 2009, annual reports from Countdown to 2015, and the development of the MNCH Consensus of $2009^{[5]}$. The process also built on the recommendations of purpose-built working groups on accountability, innovation, financing, human rights, and others, as well as the inputs of more than 300 organisations from different epistemic and professional groups, such as reproductive, maternal, newborn, child and adolescent experts, as well as governments, private businesses, UN agencies, donors, NGOs, academic organisations, and health professional associations.

The speed with which the Global Strategy was built reflected the political opportunity of the second high-level meeting on the MDGs in September 2010. All member-states of the UN were invited and the meeting was designated as a launching pad for the Strategy. This launch was facilitated by the championship of UN Secretary-General Ban Ki-moon. At that time, the child and maternal health goals ${ }^{[6]}$ were the furthest behind of the eight MDGs to be achieved by 2015, and Ban felt that acceleration could have a "multiplier effect on all the other MDGs, including poverty reduction, education, gender equality, HIV/AIDS, and environmental sustainability." ${ }^{36}$
The Secretary-General was supported in his leadership by a growing list of national leaders who had expressed concern with maternal and child health. Among them were Norwegian Prime Minister Jens Stoltenberg, who in 2007 established a "global network of leaders for the health MDGs"37; UK Prime Minister Gordon Brown and his wife Sarah Brown also led a high-profile campaign for the reduction of maternal mortality; Canadian Prime Minister Stephen Harper, who dedicated his presidency of the G8 in 2010 to an initiative on maternal and child mortality; and Chilean President Michelle Bachelet, a medical doctor with paediatric training also contributed to this campaign through this leaders' network. ${ }^{38}$ Adding to this were instrumental investments in early childhood mortality made by the Bill and Melinda Gates Foundation-particularly in childhood vaccines and malaria.

The Secretary-General's leadership behind the Global Strategy in 2010 galvanised attention from a wide range of stakeholder groups within the global reproductive, $\mathrm{MNCH}$ community. Never before had there been such high-level interest expressed for this set of issues; this created an important window of opportunity for coordinated advocacy.

Regional and global reproductive health advocacy networks such as the International Planned Parenthood Federation (IPPF), the Asian-Pacific Resource \& Research Centre for Women (ARROW), European NGOs for Sexual and Reproductive Health and Rights, Population and Development (EuroNGOs), and Development Alternatives with Women for a New Era (DAWN) secured an important victory in 2007 with the addition of MDG $5 \mathrm{~b}$ and the addition of reproductive health to the MDG framework. Many went on to be closely involved in the Global Strategy process, often collaborating with multilateral actors such as United Nations Population Fund (UNFPA) and the World Health Organization's (WHO's) Reproductive Health and Research in joint policy advocacy work. However, relatively few governments came forward as high profile champions of the reproductive health cause in the Global Strategy process, and some influential leaders in the Global Strategy process sidestepped discussion completely on key reproductive health issues, such as abortion. Such leaders included Canada's Prime Minister Stephen Harper, leader of the 2010 G8 initiative, whose Conservative party faced parliamentary controversy over whether family planning was to be included in Canada's response to its own G8 maternal health initiative. ${ }^{39}$

For their part, maternal health networks operating within wider $\mathrm{MNCH}$ networks in the early MDG era, such as the Partnership for Safe Motherhood and Newborn Health, the International Federation of Gynecology and Obstetrics, and the International Confederation of Midwives, did not abandon core policy beliefs about the centrality of reproductive rights and gender equity to maternal health. ${ }^{40}$ However, it is clear that their decision to participate in a joint $\mathrm{MNCH}$ campaign facilitated key shifts in network strategy, including declining use of traditional moral and rights-based arguments and greater use of evidence-based advocacy based on quantifiable economic and epidemiological data. ${ }^{41,42}$ This deliberate selection of rigorous evidence forms, echoing the dominant technical norms of the MDGs, ${ }^{43-45}$ can be construed as a strategic response to gain visibility and attention for maternal and child health issues, even though the MDGs themselves 
have been criticised since their inception for insufficient attention to equity and redistributive justice required for transformative global change. ${ }^{28,46,47}$

Reproductive health remains a cornerstone of the RMNCH "continuum of care" concept that fostered the creation of $\mathrm{PMNCH}$ in 2005 as a union of three separate partnerships on maternal health, newborn health, and child health. ${ }^{48}$ However, brokers in the Global Strategy process - including representatives of the delicately balanced $\mathrm{PMNCH}$ board, representing a wide range of disparate interests - did not seek to emphasise issues, such as abortion rights and sexual education of young people, that could cause rifts among stakeholders and create delay in achieving consensus (personal observation). Following the normative concerns of the MDGs themselves, discourse on rights in the final text of the Global Strategy was secondary to that of a more managerial nature, presenting $\mathrm{RMNCH}$ largely as a technical issue that could be solved with through more financial resources, greater efficiencies, data, and targeted policy choices. ${ }^{28}$

Successful technical consensus-building among stakeholders and the political championship of the Secretary-General, the G8, Bill Gates and others created a strong positive wave for the Global Strategy leading up to its September 2010 launch. Although the Strategy was developed outside of the usual UN intergovernmental channels, the document was given formal political backing through its inclusion in the official communique issued by UN member-states in relation to the high-level meeting on the MDGs. ${ }^{49}$ A measure of this support was seen in the September 2010 launch of Global Strategy itself, attended by a wide array of heads of state, UN, corporate and civic leaders, and accompanied by financial and policy commitments from about 70 stakeholders estimated at US\$40 billion. ${ }^{50}$

After 2010, the influence of the Global Strategy was felt in a number of ways. Commitments from individual stakeholders expanded from 70 to more than 400 by 2015, including nearly 100 national governments. ${ }^{51}$ An accountability framework was established to monitor resources and results of the Global Strategy, including through annual reports issued by an "Independent Expert Review Group" made up of senior academic, media, parliamentary and civil society leaders. ${ }^{52,53}$ More than a half-dozen global initiatives were developed between 2011 and 2015 to focus attention on issues raised by the Global Strategy, such as innovation, family planning, child survival, commodities, newborn health, maternal mortality, and harmonised health financing. 52,53

The rapid creation of a web of global health initiatives with separate governance arrangements, resources, and outputs have intensified the debate about leadership and accountability within the global RMNCH community, mirroring the debate in global health more generally. ${ }^{52-54}$ While this complexity can be viewed positively as an outgrowth of enthusiasm and participation by a widening pool of stakeholders, it can also be seen a visible product of the tensions and pressures within the global RMNCH community. Various coalitions responded to the success of the Global Strategy as an opportunity to reassert individual core policy beliefs and revise their specific advocacy strategies in that light.

\section{Results and Discussion}

What does the example of the construction of the Global Strategy tell us about how global policy networks use their power to produce policy outputs and impact?

Survey and interview data collected at the midway point of the 2010-2015 Global Strategy project (ie, in 2012 and 2013) reveal the differing beliefs and perceptions of coalitions about the Global Strategy and its utility as an agenda-setting and policy formulation effort, as well as reflections on negotiations and competition between coalitions within the global RMNCH community. This 'midpoint' perspective is important in order to isolate attention to the process and effects of the 2010-2015 Global Strategy; the views expressed in surveys and interviews at this time do not yet appear to be weighted with consideration of the post-2015 Sustainable Development Goals (SDGs), which supersede the MDGs and mark a necessary point of transition for the Global Strategy and Every Woman Every Child ${ }^{[7]}{ }^{34}$

Recalling Sabatier and Jenkins-Smith's delineation of three major sets of 'hypotheses', or drivers, for policy change - the competing beliefs and behaviours of advocacy coalitions, the role of external shocks in policy change, and the impact of new scientific knowledge on policy learning - the following section organises data collected from the 2012-2013 surveys and interviews in relation to these categories. Following the approach of others who have used the ACF as an informal guide to interpreting the behaviours of policy coalitions, not all of Sabatier and Jenkins-Smith's nine hypotheses are addressed in this paper. ${ }^{18}$ This paper focuses on those hypotheses most relevant to the case.

Our findings are set within a context of considerable consensus among actors about the value of the Global Strategy as a normative statement of priorities and joint action plan. For example, nearly all (22 of 24) respondents who participated in the 2013 in-depth interviews reported in this paper agreed the campaign had delivered added value, and provided a wide set of reasons to illustrate their beliefs concerning the Global Strategy and the processes that created it. These included greater political visibility for $\mathrm{RMNCH}$ because of the UN Secretary-General's personal leadership; the perception of broad technical consensus represented by the Global Strategy; the visibility of commitments made by others in supporting the Global Strategy; the catalytic value in creating innovative private-public partnerships to support the Strategy; and the emphasis on accountability through monitoring and reporting mechanisms associated with the Global Strategy, such as the Independent Expert Review Group.

These results underscore the results of the 2012 written survey of Global Strategy commitments. ${ }^{30}$ In that study, $78 \%$ of respondents $(n=168)$ indicated that advocacy was a focal area of their pledge. This exceeded several other possible focus areas, including monitoring and evaluation (70\%), research (63\%), innovation (54\%), and financing (45\%). However, a similar study in 2013 used a keyword search to identity content areas of the commitments, and found that only $46 \%$ of commitments (ie, 135 of 293) contained evidence of advocacy content. ${ }^{31}$

This apparent discrepancy suggests that, at an overarching level, many saw the Global Strategy and commitment-making 
as an advocacy process in its own right, whether or not their own commitment focused on identifiable advocacy activities. This point was articulated by most of the respondents involved in the 2013 key informant interviews reported in this paper, with $70 \%$ (17 of 24) referring, unprompted, to greater public momentum for RMNCH and/or the MDGs as a result of the Global Strategy.

Advocacy Coalitions: The Role of Shared Beliefs in Coalition Behaviours

"Actors within an advocacy coalition will show substantial consensus on issues pertaining to the policy core, although less so on secondary aspects." ${ }^{\prime 5}$

Many respondents (13 of 24) taking part in the 2013 oral interviews started from the normative idea that the global RMNCH policy community consists of multiple "camps," which the Global Strategy project has pushed closer together. These camps are understood in this paper as belonging to one of two main coalitions - the MNCH coalition and the SRHR coalition - defined on the basis of whether their major goal is one related to the survival theme of the MDGs or to a human rights-based belief in SRHR. The delineation of these two coalitions is based on participant-observation and interaction with coalition members in a wide range of meetings and conferences over the past decade, as well as document analysis of key reports, scholarly articles, and public statements.

"The Global Strategy has been important in facilitating cooperation among likeminded stakeholders, improving communication, decreasing transaction costs. It has created a common platform on which many different sectors can engage" (i19).

This idea was expressed by respondents in relation to both internal behaviours within their own organisations, as well as externally:

"It helped us make the case internally for increasing (our) commitment" (i18);

"The Global Strategy is something that has helped us over time as more agencies have bought into it. It's driven attention and expanded the global architecture. [When working with others], we can now refer to a unified strategy, which has been helpful in attracting attention for our goals" (i18);

"We would have undertaken a lot of our work anyhow on MDGs 4 and 5, but shaping this work as a Global Strategy commitment has allowed us to connect more easily with others who are doing similar work and to build on those partnerships" (i17, 2013).

For some, however, the Global Strategy process exposed preexisting conflict between coalitions, leading to unexpected consequences. Several of the oral respondents, for instance, noted that the normative concerns of the Global Strategy were those of maternal and child survival more than SRHR. Evidence for this claim includes the perceived imbalance in the text of the Global Strategy in relation to such issues. This included, on the one hand, perceived neglect to adolescent health and human rights, and on the other, a dominant focus on biomedical interventions and quantitative measurements. Family planning, for instance, was recognised in the text through the inclusion of two specific goals - preventing 33 million unwanted pregnancies and enabling 43 million new users of family planning by $2015 .{ }^{55}$ However, without a strong rights- and equity-based framework in the Strategy, these goals were seen by many to lack context and emphasis.

"We felt the Global Strategy was not as 'family-planning friendly' as it could have been - that it was very focused on maternal health, and that narrative wasn't going to resonate with the reproductive health community. But we saw an opportunity to build on the momentum that the Global Strategy had set in motion, to start our own family planning campaign, which led directly to FP2020. The Global Strategy was the spark that ignited our imagination" (i1, 2013);

"The voices of young women and girls do not come very clearly in the Global Strategy. A lot of interventions described in the Global Strategy are technical in nature, focusing on health systems and services, which doesn't address root causes of health, including education, empowerment and community leadership needs. So in shaping our commitment, we wanted to emphasise these issues" (i7).

The construction of the Global Strategy, therefore, became an arena in which coalitions competed and aligned to challenge dominant norms. While some made commitments to adolescent health and SRHR issues in order to flag up key gaps, as seen in the example above, others sought to leverage the Global Strategy much more directly, creating momentum for overlooked issues through high profile events such as the London Family Planning Summit in 2012, championed by the UK government, the Bill \& Melinda Gates Foundation, UNFPA and others. The London summit led in turn to the "FP 2020" partnership in 2013, which seeks to implement the commitments of the London Summit. As a result of these events and growing donor support for family planning, $40 \%$ of all commitments to the Global Strategy by June 2013 included family planning. ${ }^{31}$ Such shifts represented a major challenge to the "MNCH" status quo, putting pressure on the identity and membership of this global policy community to embrace a broader identity, inclusive of sexual and reproductive health, and including adolescents alongside mothers and children.

"The Global Strategy was a great step forward, as it helped shift the discourse from focusing only on maternal health and mothers to women's health. This presented a great opportunity for many stakeholders to join the movement around SRHR, and to reframe their existing commitments in this light" (i9).

\section{Policy Change: The Role of External Shifts}

"The policy core attributes of an... action programs are unlikely to be changed in the absence of significant perturbations external to the sub-system, ie, changes in socio-economic conditions, public opinion, system-wide governing coalitions, or policy outputs from other sub-systems." ${ }^{\prime 5}$

The impetus for the creation of the Global Strategy itself was the introduction of the MDG framework and the concern by leaders such as Secretary-General Ban Ki-moon that inadequate progress in reducing preventable maternal and child deaths was impeding progress towards the 2015 goals. At that time they realised it would require a dedicated global effort to turn the situation around.

The successful struggle for visibility and resources by the 
global reproductive health and rights network, seen in the examples above, was facilitated by an incipient shift in political attention to the broader social, environmental and economic determinants of health and well-being, represented by the emerging post-2015 SDGs. From the time of the Rio +20 conference in June 2012, which launched the process of negotiating the post-2015 successor goals, a new emphasis has been established on the intrinsic relationship between health and other components of development, including education, gender equity, water and sanitation, agriculture and nutrition. ${ }^{56}$

This reconceptualisation of health as a determinant, outcome and indicator of sustainable development has enlarged the arena for participation by a wide range of health actors. ${ }^{57}$ This includes the women's health community, which sought to 're-politicise' SRHR issues in the MDG era by rejecting the narrow technical focus of the MDGs on maternal mortality, and embracing debate on the inter-connectedness of health issues and the distribution of power and resources. ${ }^{28}$

The growing power of the reproductive health community can be measured by the growing number of commitments to the Global Strategy. Conversely, it is also clear from the experience of the 2010-2015 Global Strategy that the production of such consensus-based policy documents may reflect short-term tactical opportunities, such as seizing attention at a high-level meeting on the MDGs, rather than reflecting genuine shifts in core policy beliefs through compromise and negotiation. Annual progress reports on the commitments, for example, continue to report at least a partial mismatch between the Global Strategy's "priority" countries and interventions, and those actually prioritised by commitment-makers. ${ }^{30,31}$ An example of this is the high number of commitments made by stakeholders to India and South Africa (31 and 15 commitments, respectively, as of June 2012), although neither country was named on the Global Strategy's list of 49 priority countries. ${ }^{30}$ Similarly, countries such as Somalia, whose child and maternal mortality rates were high with poor progress, received just seven commitments in 2012.

This finding is also echoed in the interviews for this paper, with less than a third of oral respondents (7 of 24) reporting that the Global Strategy had influenced their policy priorities in any meaningful way. This includes six of seven senior government representatives interviewed: "The Global Strategy only validates our own policy and programming approach" (i15).

This may be especially so for commitment-makers with the greatest access to power and resources, including the private sector. Representatives of private sector commitmentmakers were especially explicit about their tactical use of the commitment process, with only three of five reporting that the Global Strategy was instrumental to guiding their investments, and then only when that guidance cohered with existing business strategies, including strengthening market position.

"The focus on PPPs (private-public partnerships) in the Global Strategy helped us to think that others understand our business ideas and are mobilising support for them" (i14);

"The Global Strategy has provided a kind of framework for our investment areas. There are six or seven areas in the Global Strategy, and we selected two of them" (i23);
"We saw the Global Strategy as an opportunity to position ourselves as a global leader in providing healthcare, as well as to help us focus on our existing niches and how to integrate these into the public sector, working with public stakeholders" (i18). This research finds, therefore, that external stimuli can have an important effect on the behaviours of advocacy coalitions, such as cooperating with each other to produce an effective policy response when opportunities arise. However, such behaviours are largely tactical in nature and do not necessarily reflect sustainable shifts in core policy beliefs.

Policy Learning: The Role of Scientific Evidence and Policy Brokers

“(a) Policy-oriented learning across belief systems is most likely when there is an intermediate level of informed conflict between... coalitions $^{[8]}$;

(b) Policy-learning across belief systems is most likely when there exists a forum that is prestigious enough to force professionals from different coalitions to participate, and is dominated by professional norms."15

Sabatier and Jenkins-Smith's framework identifies a second major avenue for changes in policy beliefs among coalitions. This is through the adoption of new technical evidence and "policy learning" acquired with experience and time. The preceding informant quote about how the Global Strategy shifted the discourse "from focusing only on maternal health and mothers to women's health" illustrates the existence of policy learning between the $\mathrm{MNCH}$ and $\mathrm{SHRH}$ coalitions that occurred during the course of collaboration in the production of the document. At the same time, the overall lack of a rights-based framework to the Global Strategy illustrates the existence of compromise and the limits to such shifts in secondary beliefs.

The productive power of the MNCH community, wielded through its scientific and quantitative assessments of progress in mortality reduction, aligns well with the technical orientation of the MDGs. ${ }^{58}$ This evidence often takes the form of empirical data generated by scientists such as epidemiologists and economists. The Countdown to 2015 network, led by highly regarded academics such as Cesar Victora, Jennifer Bryce, and Zulfiqar Bhutta, was particularly influential in this regard, publishing a broad range of data products that set the pace for MNCH measurement during the MDG era. Concepts of 'progress', therefore, often follow these quantitative forms, promoting shared concepts and setting terms of debate about how change happens. The 2013 publication of a Global Investment Framework for Women's and Children's Health, for instance, presented economic evidence to strengthen the concept of health as an investment that generates social benefits and capital returns. ${ }^{59}$

At the same time, prioritisation of quantitative evidence can exclude, for instance, more normative and political measures of change, vital to understanding complex social phenomena involving structural barriers, such as inequities based on gender, class, race or geography. ${ }^{43}$ Differing ideas about how progress is measured is evident within the global $\mathrm{RMNCH}$ community, with reproductive health coalitions calling for a more explicit recognition of the political nature of change, the links between health and its determinants, and the role of collective action in realising rights. ${ }^{28}$ As such, "policy 
learnings" means different things to different stakeholders, as do the concepts of progress, accountability and governance. For some, accountability is measured through independent performance-based scorecards; for others, it is a process of mutual dialogue between stakeholders at all levels: for others, rights and entitlements are secured and measured through legal frameworks and conventions.

Respondents participating in the 2013 oral interviews displayed a wide range of beliefs in how progress and learning are best measured, including through comparison with other networks and in relation to global governance norms (or the lack thereof):

"Having heard about the Global Strategy at the 2010 UN

General Assembly to review progress on the MDGs in New

York, we decided to contribute to the goals of the Global

Strategy alongside other countries. The motivation was to compare our progress" (i16).

The UN Secretary-General's Office, together with the $\mathrm{PMNCH}$, were positioned in the Global Strategy development process as neutral "brokers," facilitating consensus between different networks - including those representing "normative" MDG 4 and 5 interests and those representing SRHR. Yet the absence of clear governance principles and rules around the implementation of the Global Strategy facilitated the proliferation of global initiatives, often described in the 2013 oral interviews as a matter of concern because of their rapid development and potential for confusion (i24, i15).

In this sense, the ongoing debate about governance and accountability in the global RMNCH community - who, how, and using which indicators - mirrors that of the wider global health community, where the behaviours and beliefs of networks play a significant role in policy-making.

\section{Conclusion}

The case of the 2010-2015 Global Strategy for Women's and Children's Health is analysed in this paper to explore how global policy networks - rising in number and influence in the global health arena - seek and achieve power over policy and resources. This portrait of the hidden role of politics within policy-making processes illustrates how global advocacy coalitions, bound by shared core beliefs and behaviours, but diverging secondary beliefs, compete and collaborate with each other in a strategic effort to influence policy agendas. This study, therefore, concludes with three observations based on the case presented. First, competing coalitions with different policy beliefs, norms and strategies can collaborate productively with each other for policy influence if incentives and conditions are sufficient to facilitate this collaboration. In this case, the MDGs offered a time-bound opportunity for networks to come together to build a joint Global Strategy and common advocacy platform to attract political attention and resources for the benefit of all networks.

Second, while such collaborations may be framed as examples of successful, "consensus-based" efforts, ${ }^{60}$ they do not necessarily imply fundamental shifts in policy beliefs among disparate networks, and can instead represent a short-term tactical response to unexpected events and opportunities, such as the offer of the UN Secretary-General to champion the cause of women's and children's health. The depiction of the Global Strategy as a 'consensus' project, despite significant underlying differences in beliefs between the $\mathrm{MNCH}$ coalition and the SRHR coalition, was an effective response to a time-bound opportunity, since it projected a positive and confident image of a "global RMNCH community" united in its knowledge, norms, and behaviours - an attractive picture to would-be investors and champions, no matter which side of the MNCH-SRHR divide.

Third, this paper finds that the ACF successfully predicts the slow evolution of network core beliefs. However, minor or secondary views - such as those expressed by "evidencebased" frames to gain political attention - can and do change in response to shared experience, new evidence, and opportunity/events. The 2015 development of an updated Global Strategy for the 2016-2030 period, ${ }^{61}$ for instance, puts far greater focus on human rights and social and economic determinants of health compared with the 2010 Global Strategy. This increased focus reflects the difference between the more utilitarian MDGs and more rights-based SDGs. The new document also reflects changes over time of the $\mathrm{MNCH}$ and SRHR coalitions. The MNCH coalition appears to have come to terms with the inherit merits and 'messiness' of a harder to measure rights-based approach to health, while the SRHR coalition has seen that scientific discourse and quantifiable indicators can attract investment and political attention that in turn can enable advancements of its own rights-based agenda.

On the whole, the Global Strategy case suggests that, under the right circumstances, even competing ideas and beliefs held by different policy networks can blend effectively into a shared policy product that benefits all actors, at least temporarily while windows of opportunity remain open.

As Shiffman observes, power struggles are inextricably part of the global health landscape, including in relation to the important role of networks in governance reform. ${ }^{62}$ Scientific evidence is vital to advancing progress, but normative questions of resource allocation and equitable provision of public goods require political and social debate that empirical methods alone cannot address.

In this sense, this study of power relations among networks suggests that there is a highly productive role for politics in global public health. Far from seeing policy-making at the global level as a neutral process to be guided by principles and science, and protected from politics, this paper concludes that contention and debate is indeed vital to progress, lending greater legitimacy, accountability and transparency to the policy process.

\section{Acknowledgements}

Professor Emeritus Gill Walt of the London School of Hygiene and Tropical Medicine, London, UK and Professor René Véron of the University of Lausanne, Lausanne, Switzerland provided insightful and constructive comments on this article.

Authors' contributions

LM is the sole author of this article, responsible for study design, research, analysis, and drafting

\section{Ethical issues}

Ethical approval for this study was granted by the London School of Hygiene and Tropical Medicine, London, UK as part of the author's doctoral research project. The analysis of this paper belongs to the author alone; findings were not 
reviewed or endorsed by partnership for maternal, newborn, and child health (PMNCH).

\section{Competing interests}

LM was a staff member of the partnership for maternal, newborn, and child health $(\mathrm{PMNCH})$ during the research and writing of this article, which was undertaken to fulfil, in part, the requirements of a doctoral dissertation at the London School of Hygiene and Tropical Medicine, London, UK. The findings and interpretation in this paper do not represent those of the $\mathrm{PMNCH}$, and are attributable only to LM.

\section{Endnotes}

[1] MDG 4 calls for reducing under-five child mortality by two-thirds by 2015; MDG 5 calls for reducing maternal mortality by three-quarters by 2015 and achieving universal access to reproductive health.

[2] Sabatier and Jenkins-Smith ${ }^{15}$ define a policy sub-system as "consisting of those actors from a variety of public and private institutions who are actively concerned with a policy problem or issue, and who regularly seek to influence public policy in that domain."

[3] Q6: "What was the added value of making this commitment in association with the Global Strategy? Would you have made this commitment if the Global Strategy did not exist? Why/why not? Did the Global Strategy influence your focus on particular interventions/services in your commitment?"

[4] PMNCH (http://www.pmnch.org/), a global alliance of more than 700 member organizations, played a facilitating role in the development of the Global Strategy in 2010. PMNCH continues to advocate for Every Woman Every Child and to track progress of commitments.

[5] http://www.who.int/pmnch/knowledge/publications/2009_mnchconsensus/ en/.

[6] MDG 4 sought to reduce under-five child mortality globally by two-thirds by 2015 against a 1990 baseline; MDG 5 sought to reduce the maternal mortality ratio by three-quarters on a global level during the same time period, as well as achieve universal access to reproductive health by 2015 . The reproductive health goal was added in 2007 after successful advocacy by sexual and reproductive health and rights networks. ${ }^{35}$

[7] An updated version of the Global Strategy (Survive, Thrive, Transform: The Global Strategy for Women's, Childrens' and Adolescents' Health, 2016-2030) launched in September 2015 alongside the new Sustainable Development Goals.

[8] Sabatier and Weible assume that within policy sub-systems, actors are aggregated into "two to five" advocacy coalitions or "informal networks,"22 composed of specialists from both governmental and private organisations. These actors share a set of normative and causal beliefs and engage in a "non-trivial degree of coordinated action over time." ${ }^{15}$ This coordination can be relatively weak (eg, monitoring activities of allies) or strong in nature (eg, developing a common implementation plan).

\section{References}

1. Keck M, Sikkink K. Activists Beyond Borders: Advocacy Networks in International Politics. Cornell, NY: Cornell University Press; 1998.

2. Fidler DP. Architecture amidst anarchy: global health's quest for governance. Glob Health Gov. 2007;1:1-17.

3. Bruen C, Brugha R. A ghost in the machine? Politics in global health policy. Int $J$ Health Policy Manag. 2014;3(1):1-4. doi:10.15171/ijhpm.2014.59

4. McCoy D, Singh G. A spanner in the works? anti-politics in global health policy: Comment on "A ghost in the machine? politics in global health policy." Int J Health Policy Manag. 2014;3(3):151153. doi:10.15171/ijhpm.2014.77

5. Harmer A. Democracy - the real 'ghost' in the machine of global health policy: Comment on "A ghost in the machine? politics in global health policy." Int J Health Policy Manag. 2014;3(3):149150. doi:10.15171/ijhpm.2014.75

6. Shiffman J. Knowledge, moral claims and the exercise of power in global health. Int J Health Policy Manag. 2014;3(6):297-299. doi:10.15171/ijhpm.2014.120

7. Rushton S, Williams OD, eds. Partnerships and Foundations in Global Health Governance. London: Palgrave Macmillan; 2011.

8. Biesma RG, Brugha R, Harmer A, Walsh A, Spicer N, Walt G.
The effects of global health initiatives on country health systems: a review of the evidence from HIVIAIDS control. Health Policy Plan. 2009;24(4):239-252. doi:10.1093/heapol/czp025

9. Warren AE, Wyss K, Shakarishvili G, Atun R, de Savigny D. Global health initiative investments and health systems strengthening: a content analysis of global fund investments. Global Health. 2013;9(1):30. doi:10.1186/1744-8603-9-30

10. Frenk J, Moon S. Governance challenges in global health. N Engl JMed.2013;368(10):936-942.doi:10.1056/NEJMra1109339

11. Fidler D. The challenges of global health governance. Working Paper. New York: Council on Foreign Relations; 2010.

12. Sidibe M, Buse K. AIDS governance: best practices for a post2015 world. Lancet. 2013;381(9884):2147-2149. doi:10.1016/ S0140-6736(13)61413-0

13. Horton R. Offline: the uses of discomfort. Lancet. 2015;385(9971):840.

14. Sabatier PA. An advocacy coalition framework of policy change and the role of policy-oriented learning therein. Policy Sci. 1988;21:129-168.

15. Sabatier PA, Jenkins-Smith HC. The Advocacy Coalition Framework: An Assessment. In: Sabatier PA, ed. Theories of the Policy Process. Boulder CO: Westview Press; 1999:117-166.

16. Della Porta D, Diani M. Social Movements: An Introduction. Oxford: Blackwell; 2006.

17. Nelson PJ. Human rights, the Millennium Development Goals, and the future of future of development cooperation. World Dev. 2007;35(12):2041-2055.

18. Larsen JB, Vrangbaek K, Traulsen JM. Advocacy coalitions and pharmacy policy in Denmark--solid cores with fuzzy edges. Soc Sci Med. 2006;63(1):212-224. doi:10.1016/j. socscimed.2005.11.045

19. Benford RD, Snow DA. Framing processes and social movements: an overview and assessment. Annu Rev Sociol. 2000;26:611-639.

20. Kingdon JW. Agendas, Alternatives and Public Policies. Boston: Little, Brown; 1984.

21. Jenkins-Smith HC. Evaluating the Advocacy Coalition Framework. J Public Policy. 1994;14:175-201.

22. Sabatier PA, Weible CM. The Advocacy Coalition Framework: innovations and clarifications. In: Sabatier PA, ed. Theories of the Policy Process. Boulder CO: Westview Press; 2007:189-220.

23. Farquharson K. Influencing policy transnationally: pro- and anti-tobacco global advocacy networks. Aust $J$ Public Adm. 2003;62:80-92.

24. Koplan JP, Bond TC, Merson MH, et al. Towards a common definition of global health. Lancet. 2009;373(9679):1993-1995. doi:10.1016/S0140-6736(09)60332-9

25. Weible CM, Sabatier PA. A guide to the Advocacy Coalition Framework. In: Fischer F, Miller GJ, eds. Handbook of Public Policy Analysis: Theory, Politics \& Methods. Boca Raton, FL: CRC Press; 2007:123-136.

26. Litfin KT. Advocacy coalitions along the domestic-foreign frontier: globalization and Canadian climate change policy. Policy Stud J. 2000;28:236-252.

27. Diaz-Martinez E, Gibbons E. The questionable power of the Millennium Development Goals to reduce child mortality. J Human Dev Capabil. 2014;15:203-217.

28. Yamin AE, Boulanger VM. Why global goals and indicators matter: the experience of sexual and reproductive health and rights in the Millennium Development Goals. J Human Dev Capabil. 2014;15(2-3):218-231.

29. Yin RK. Case Study Research: Design and Methods. 5th ed. Thousand Oaks, CA: Sage; 2014.

30. Partnership for Maternal Newborn and Child Health. The PMNCH 2012 Report: Analysing Progress on Commitments to the Global Strategy for Women's and Children's Health. http://www.who. int/pmnch/topics/part_publications/2012_pmnch_report_full 
publicaton.pdf. Published 2012.

31. Partnership for Maternal Newborn and Child Health. The PMNCH 2013 Report: Analysing Progress on Commitments to the Global Strategy for Women's and Children's Health. http:// www.who.int/pmnch/knowledge/publications/pmnch_report13. pdf. Published 2013.

32. Krippendorff K. Content Analysis: An Introduction to its Methodology. 3rd ed. Thusand Oaks, CA: Sage; 2004.

33. Walt G, Shiffman J, Schneider H, Murray SF, Brugha R, Gilson L. 'Doing' health policy analysis: methodological and conceptual reflections and challenges. Health Policy Plan. 2008;23(5):308317. doi:10.1093/heapol/czn024

34. Bustreo F, Gorna R. Knowledge for effective action to improve the health of women, children and adolescents in the post-2015 era: a call for papers. Bull World Health Organ. 2015;93(5):286286A.

35. Fukuda-Parr S, Hulme D. International Norm Dynamics and 'the End of Poverty': Understanding the Millennium Development Goals (MDGs). http://www.bwpi.manchester.ac.uk/medialibrary/ publications/working_papers/bwpi-wp-9609.pdf. Accessed 2015. Published 2009.

36. Ban KM. Empowering women to change the world. Philadelphia, PA: Speech given to the Global Colloquium of University Presidents; 2011.

37. NORAD. Global Campaign for the Health MDGs: Prime Minister Jens Stoltenberg launched the Global Campaign for the Health MDGs in New York in September 2007. http://www.norad.no/en/ front/thematic-areas/global-health/maternal-child-and-womenshealth/global-campaign-for-the-health-mdgs/. Accessed October 11, 2015. Published 2015.

38. The Partnership for Maternal, Newborn \& Child Health (PMNCH). Investing in Our Common Future: Healthy Women, Healthy Children. http://www.who.int/pmnch/media/ events/2009/20090923_mnchconsensusstory/en. Accessed October 9, 2015. Published 2009.

39. Ibbitson J. Contraception a part of maternal-health plan, Harper says. The Globe and Mail. 2010. http://www.theglobeandmail. com/news/politics/contraception-a-part-of-maternal-health-planharper-says/article4312322/

40. Langer A, Horton R, Chalamilla G. A manifesto for maternal health post-2015. Lancet. 2013;381(9867):601-602. doi:10.1016/ S0140-6736(13)60259-7

41. Storeng KT, Mishra A. Introduction. Politics and practices of global health: critical ethnographies of health systems. Glob Public Health. 2014;9(8):858-864. doi:10.1080/17441692.2014 .941901

42. Starrs AM. Safe motherhood initiative: 20 years and counting. Lancet. 2006;368(9542):1130-1132. doi:10.1016/S01406736(06)69385-9

43. Storeng KT, Behague DP. "Playing the numbers game": evidence-based advocacy and the technocratic narrowing of the Safe Motherhood Initiative. Med Anthropol Q. 2014;28(2):260279. doi:10.1111/maq.12072

44. Fehling M, Nelson BD, Venkatapuram S. Limitations of the Millennium Development Goals: a literature review. Glob Public Health. 2013;8(10):1109-1122. doi:10.1080/17441692.2013.845 676

45. Ziai A. The Millennium Development Goals: back to the future. Third World Q. 2011;32:27-43.

46. Saith A. From universal values to Millennium Development Goals: lost in translation. Dev Change. 2006;36:1167-1199.

47. Kabeer N. Tracking the gender politics of the Millennium Development Goals: struggles for interpretative power in the international development agenda. Third World Q. 2015;36:377395.
48. Kerber KJ, de Graft-Johnson JE, Bhutta ZA, Okong $P$, Starrs A, Lawn JE. Continuum of care for maternal, newborn, and child health: from slogan to service delivery. Lancet. 2007;370(9595):1358-1369. doi:10.1016/S01406736(07)61578-5

49. United Nations. Outcome document of the high-level plenary meeting of the sixty-fifth session of the General Assembly on the Millennium Development Goals. http://www.un.org/en/ mdg/summit2010/pdf/Draft\%20outcome\%20document.pdf. Published 2010.

50. United Nations. UN Summit launches drive to save the lives of more than 16 billion women and children. http://www. un.org/en/mdg/summit2010/pdf/GLOBAL\%20STRATEGY\%20 PRESS\%20RELEASE\%20FINAL\%20FINAL3_2_.pdf. Published 2010.

51. Partnership for Maternal Newborn and Child Health (PMNCH). The PMNCH 2014 report: tracking financial commitments to the Global Strategy for Women's and Children's Health. http:// www.who.int/pmnch/knowledge/publications/pmnch_report14. pdf?ua=1. Published 2014.

52. Independent Expert Review Group. Every Woman Every Child: strengthening equity and dignity through health. http://apps. who.int/iris/bitstream/10665/85757/1/9789241505949_eng.pdf. Published 2013.

53. Independent Expert Review Group. Every Woman Every Child: a post-2015 vision. http://apps.who.int/iris/ bitstream/10665/132673/1/9789241507523_eng.pdf. Published 2014.

54. Godwin P, Misra S. The Every Woman Every Child health-model of accountability in the post 2015 era: a multi-constituency platform to track accountability. http://www.who.int/pmnch/ about/governance/partnersforum/2b_godwin_misra.pdf?ua=1. Published 2014.

55. United Nations. The Global Strategy for Women's and Children's Health. http://www.who.int/pmnch/topics/maternal/20100914_ gswch_en.pdf?ua=1. Published 2010.

56. United Nations. The road to dignity by 2030: Ending poverty, transforming all lives and protecting the planet: Synthesis report of the Secretary-General on the post-2015 agenda. http://www. un.org/disabilities/documents/reports/SG_Synthesis_Report_ Road_to_Dignity_by_2030.pdf. Published 2010.

57. Buse K, Hawkes S. Health in the sustainable development goals: ready for a paradigm shift? Global Health. 2015;11:13. doi:10.1186/s12992-015-0098-8

58. Fukuda-Parr S, Yamin AE, Greenstein J. The power of numbers: a critical review of Millennium Development Goal targets for human development and human rights. J Human Dev Capabil. 2014;15:105-117.

59. Stenberg K, Axelson $\mathrm{H}$, Sheehan $\mathrm{P}$, et al. Advancing social and economic development by investing in women's and children's health: a new Global Investment Framework. Lancet. 2014;383(9925):1333-1354. doi:10.1016/S0140$6736(13) 62231-X$

60. United Nations. Saving lives, protecting futures: progress report on the Global Strategy for Women's and Children's Health. http:// www.everywomaneverychild.org/images/EWEC_Progress_ Report_FINAL_3.pdf. Published 2015.

61. United Nations. Global Strategy for Women's, Children's and Adolescents' Health, 2016-2030. http://www.who.int/lifecourse/partners/global-strategy/global-strategy-2016-2030/en/. Published 2015.

62. Shiffman J. Global health as a field of power relations: a response to recent commentaries. Int J Health Policy Manag. 2015;4(7):497-499. doi:10.15171/ijhpm.2015.104 